\title{
Architectural Value and Urban Metabolism and the post-oil city as transition to what comes after.
}

\author{
Michael KARASSOWITSCH, V-SPARC VIT University, India
}

\begin{abstract}
This paper contributes to the evolutionary transition of urban environments, which the city represents, through the supposition that the post-oil period is transitional toward introducing architectural value that may serve realizing metabolism in settlements. This paper interweaves urbanity, architectural value and the practice of its provision to describe this transformative evolution. The words 'city' and 'urban' are commonly used interchangeably and are tacitly opposed to the land, nature and its life, including rurality. Ubiquitous urban interactivity is proposed as narrow technological valuation based on scientific parameters that do not comprehend nature's reality and the quality of life, love, consciousness and its purpose.

This paper references spiritual practice to show that architectural value is inclusive of these essential elements. Conceptual project-based thinking of architectural practice draws architectural value to the wider planning level to invoke true metabolism. Four parameters of urbanity point to evolving cities' metabolic quality and efficiency beyond physical and psychological health. The work of a studio project located at peri-city areas of Vellore in India expresses these parameters in action. The cooperative whole of settlements in nature, architectural value as high quality environments that translate and support high quality society, as forms of wellbeing and daily life satisfaction, with socially integrated purpose, serve to evolve settlement metabolism essential to human responsibility.
\end{abstract}

\section{Keywords}

Architecture, Spirituality, Nature, Metabolism, Technology, Urban

\section{Interrelating urbanity, rurality and architecture in light of post-oil cities.}

This paper contributes to evolving the urban environment as globalized territory through understanding the post-oil period as a period of great change toward a new paradigm, which creates urban metabolism. 'Post-oil' is understood as counter to the use of oil and not yet the period that will follow. Metabolism is taken in the wider sense of whole life systems, where the energy input includes the human spirit. The end of mineral oil energy and material indicates this paradigm change, which climate change, biosphere collapse and its re-organization as 'other' and the vulnerability expressed through the current pandemic and our reactions signal to us. This paper interweaves the existing paradigm of urbanity and the city, architectural value and the practice of architecture's provision to describe enabling our coming transformational period through realizing architectural value.

'City' is proposed as an intensity of urbanity, while urbanity has covered the globe. The city is our common focus due to it housing high consumption of material and energy (even if it is less intensive percapita), and financial and economic centres. It symbolizes our civilization and houses the control and power of 'urban' environments and. The needs that great expansion of humanity has, both in numbers having doubled over a life-time - and personal consumption, have extended the urban condition far beyond the intensity of city pin-points. Supplying the city with resources extends over the horizon and deep into the ocean. The system of urbanized striation, valuation and communication is now a global 
ubiquitous condition, while the character, depth and breadth of non-city urban is not clearly taken into consideration. Instead, the words 'city' and 'urban' are commonly used interchangeably, tacitly opposing urbanity-as-city to the rest of the world. We create a false definition by opposing, the 'village' to 'city'.

To explore globally ubiquitous urban space we may consider 'rurality'. The relationship of the urban to nature and to rurality, and nature to rurality, is profoundly important as the present status quo dissolves and evolves. In India, villages and towns are integrated with the landscape, retaining or having had a basis or one of harvesting from nature, most often farming, but also wood, minerals or sea food, by which they were founded and formed. They are tied to the land in a complex but simple way retaining the geographic and life forms of the land and are more interactive with and more directly dependent on the earth's life. Rural places assert a relationship to the Land that supersedes the pervasive urban striations across the world and they are also different from 'being in nature'. How do they assert that? A clue is found in the past century's governments' eradication of indigenous and nomadic cultures. These cultures occupy rural territories that the techno-city urban field needs to re-territorialize with striations and limits for the sake of creating reserves and control points of the financial flows it generates. In North America, native people and the buffalo and caribou that travelled great migratory routes, are not permitted. They contradict the static urban structure of economy of ownership and finance based capital management rather than stewardship. The land is parcelled into production units. Rural places are now generally in a functional relationship with urban structures, e.g. the economy of farming in landscapes that are under the influence of urban structures and systems. Their output is far beyond local needs, with the economy demanding that output and offering material increase and wider communication. They serve urban centres which is coordinated by them financially.

Urbanity organizes the land for specific tasks in terms of attributes. This is as simple as slopes for drainage or for collection of water, limits for erosion and vehicular movement, lakes to sequester toxic materials, or proximity to transport and economically derived centres. The issue is in how these are thought in light of need and context. Urbanizing structures include industrial farming to harness nature ever more deeply, 'enframing' nature, using Heidegger/Lovitt's term, according to technological production values, based on that isolate answerable questions in terms of problems and solutions. Urban systems overlay the natural environment. Urban structures appear as cuts and deformation in a natural setting, appearing as damage in most cases. Figure 1. Urbanized intensities and intensively farmed areas cause profound diminishment of life. We do not often experience the urban as such in a natural or rural setting. Figure 1. Nevertheless, we all feel the quality of rurality. Rurality suggests a threshold to how its qualities will absorb ubiquitous urbanity of technological processes that dismember nature's metabolism.

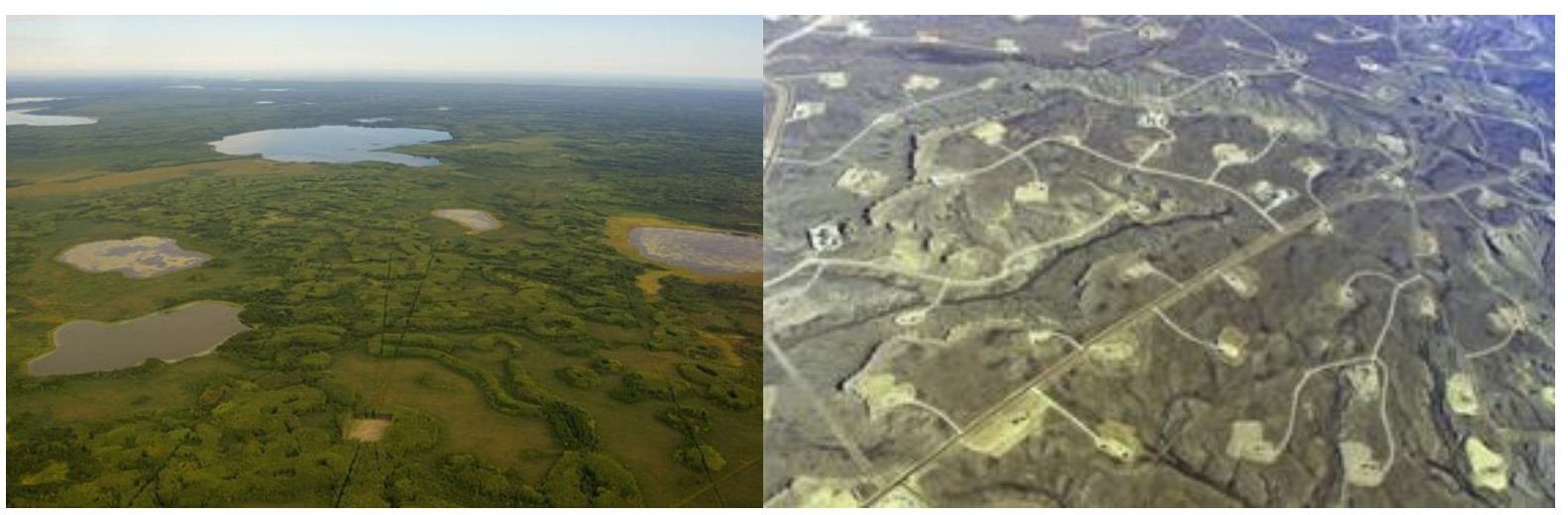

Figure 1. Left: Seismic testing lines through the northern Canadian boreal forest. Right: Fracking site in Wyoming, USA. The form is suburban, but each station is toxic and bare of life. Source: Unknown.

I propose to reverse for many readers the concept that we are in the natural world, huddled in towns and cities. It is now the rural that ekes out its corners lovingly and beloved of its citizens. It is the rare valley such as the Incomappleux in Canada that is free from urban overlays. Figure 2. 


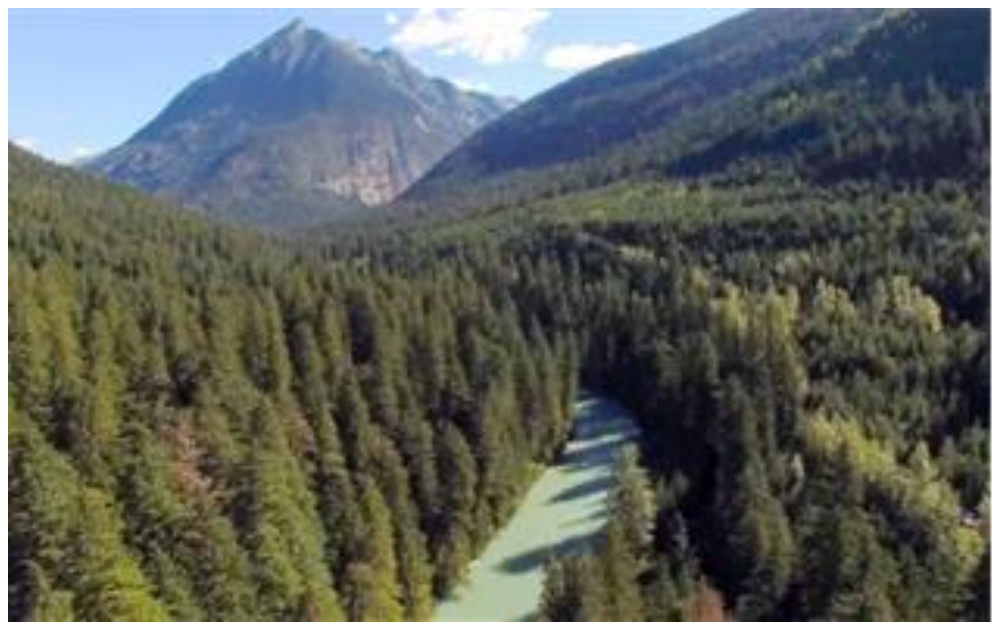

Figure 2. The Incomappleux Valley in British Columbia, Canada remains not-urban. Source: Gillis 2016.

\section{Technology as Other to Nature}

Nature and its life are understood today through technological and scientific valuation as quantification of narrowly appropriated parameters that do not comprehend what cannot be asked as a scientific question. Karl Popper clarified this by challenging the 'method/inference' model that science generally holds with his concept of 'falsifiability' which says that, "A theory is scientific only if it is refutable by a conceivable event." (Thornton 2018) This indicates clarifies what science, and the technology based on it, represents. Modern science is method that leads to decisive conclusions to posed theses. Planning promotes 'inferences' in the same sense. We intend objective proven tenets that require parameters that 'enframe' the world according to the technologically defined purpose at hand. What cannot be measured becomes exterior to, or concealed as, technology. (Karassowitsch 2015)

Urbanity engages this. Nature's reality eludes our technological urban-encoded landscape. Nature is 'the other' in this arrangement, and is often seen as an enemy. Rural life is often seen as backward according to the advancements commonly accepted as part of a technology driven future. 'Progress' is based in technology and its material values correspond as financial assets. The excluded, unspoken, un-integrated and concealed aspects of world include almost everything that makes us human, such as capacity to grasp nature's not-systems and purpose, the source and nature life, love, consciousness and its purpose, and life's value for its own sake. Elements of metabolism can be represented technologically, but metabolism is not technological. Where the measure of life and consciousness is determined, it is only partial as circumstantial or signified 'enframed' reserve. The difficulty of thinking other to the concealing technicist tropes of our culture is because the concealing of (our) mind is itself concealed. Architectural practice and urban planning often intend the same concealing. The use of styles in the 19th century is exemplary. The proper application of a style was socially safe both in terms of opinion and any lack of skill on the architect's part. Ruskin expressed this very clearly. (Ruskin 1984 Obedience). This eclecticism of styles by 19th century architects has migrated to building technology in Modern and Post-modern architecture in which 'proper' technology is used to signify architectural merit according to the technicist economy and finance by which a project gets its approval. This is taken as scientific and reasoned, but the vast failure for betterment belies lack of need based reason. Success is largely determined by wealth to suppress and extract value, and displacement of waste and pollution to distant place or into seemingly silent nature. The terror of our environmental disaster is that it is the result of absence. It is not what we are doing so much as the absence that leaves us irresponsible stewards. To understand this we must look beyond technological reasoning to the concealed attributes of consciousness. 


\section{The Role of Consciousness and Evolving the Built World as Architecture}

That we are continuously improving our urban environments can be questioned based on evidence is that improvement of cities with current technological concepts is a context for unsustainable cultures that do not support large proportions of our populations nor nature properly at all. Even those that are appear stable require material wealth production that the earth's environment cannot sustain. The material and energy inputs of modern technological processes required for their form of culture are those responsible for extracting and harvesting energy and matter on narrow parameters that leave the nature of Gaia staggered and at the threshold of deep perennial change. However, cut that enabling wealth, which includes finance and banking, in countries like Austria, Germany and Switzerland, and they should nevertheless be well placed compared to 150 years ago. We would not forget essential knowledge, including material gains understood through the modern machine ages technology.

To claim that our urbanism has a metabolism is aspirational and euphemistic. The systems we use are a facsimile of metabolism, which is a natural condition. We are far from having even 'circular' systems. Cities and the world suffer from fatal metabolic issues. Our systems depend on the generosity of nature as it was constantly filling it with new energy, while we struggle to embalm our built environments to 'conquer time'. Urban metabolism as machine age technology city versus rural spaces and nature will come to a close with the change required of large components of our built environment.

This is not as frightening as it may seem. We rely more on our inner experience than we do on what our systems appear to give us. It is possible to move beyond the need for belief in matter and technological systems and to be able to say, "I don't need belief, I know". Our individual inner worlds demand the focus on improvement that we have lavished on the outer world. Planners create in the world what they think. When we look at this from the point of view of wellbeing, accepting that we are consciously aware and rely on that every day for everything we do, urban metabolism must include conscious awareness so that the human made world might one day join the metabolism of the earth.

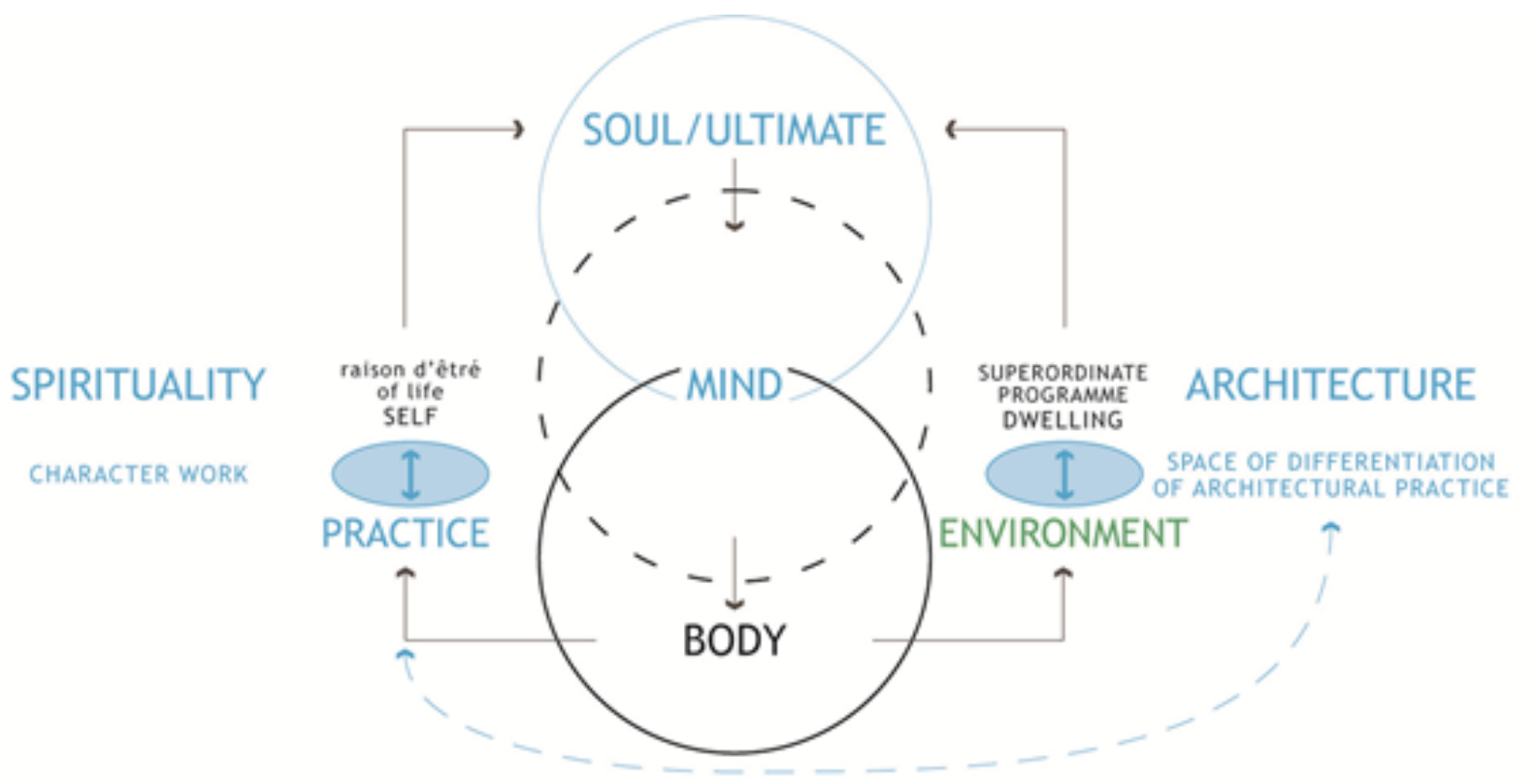

Figure 4. Diagram of the relationship of planning practices of spirituality and architecture. Spirituality on the left has its own goal. On the right, architecture is formed by and serves spirituality. Source: Author.

There is ample evidence that it is our inner spiritual world that many of us need to evolve in order to generate a life that functions with the greatest possible value. Spiritual practice, which is ancient and ongoing, develops this. These practices include șașțitantra, Buddhism, sāṃkhya, gnostic forms of Christianity (Cloud 2005), the many approaches of hathayoga and rajayoga (Vivekananda 1978), e.g. 
Heartfulness/Sahag Marg, and others. Such practices and the sciences behind them are tested over millennia. These practice are for evolving consciousness. They support and are guidance for higher quality of settlements that provide for architecture, engaging qualities that technological science cannot measure. Figure 4.

If we no longer accept improvement of urban orientated technological means as 'progress' because it does not inherently support wellbeing or the earth's natural capacity, what is available to us? Looking back to rural culture, or to ancient guided forms of living and architecture makes clear that humanity has assets of thinking and understanding. Evolving thought and wisdom in the face of the environment that we have created, seeking the essential base from which all this arises as it reaches a critical terminal change, make these past forms impossible to fit into. It must be through refining the role of human consciousness and its role in the world that new form is found. This is commonly named spirituality. Architecture inherently leverages this. Architecture has for millennia been the worldly manifestation of the need and the discovery of our role in the world because of this link. A vision for after-technology planning has as its base the conception of human life as an essential role in the life of the earth. This is not merely poetic. It is far beyond sustainability. It is the value toward which the post-oil city will be transitional. Architecture is already accepted by the vast majority of people, which is a blessing.

\section{Architecture's Capacity}

Architecture is proposed as a superordinate outcome of planning and settlement development in conscious awareness. Material, construction, technology and systems in building, design and planning architecture are considered planning's means. Although material means are intertwined with our needs and intentions, those are not architecture.

Architecture is a common human capacity based in mind and its conscious awareness that has long been required as we need to change our environment to accommodate ourselves. This is not about problems. It was part of humanity long before our present Modern machine ages mineral hydrocarbon and electricity based technology and its economy and cultures. We recognize architecture even if it was made in cultures other to our own or in vernacular structures (Rudofsky 1964), and in the distant past. Architecture comprehends human consciousness that demands recognition of being and purpose. But we are attending to technicist reduction to physical and material needs, defying our capacity and relevance to the planet, to Nature and our own wellbeing.

The positive aspect that founds architecture is aspiration. When any situation is dealt with consciously, human aspiration is addressed. A locus that we call architecture is, therefore, not physically objective architecture. Our experience of such an intentional environment is how we attain architecture. Our individual awareness is re-formed when we experience architecture 'presencing'. Architects prepare such loci for unknown persons to experience as architecture, be it an alcove, a room, a building or a sector of a city. Many such places are symbolic of architecture, which overshadows their experience, becoming an objective verity. Leonardo Da Vinci's Mona Lisa is an object that means 'great painting' so much so that it replaces its experience. See Figure 5. The experience of presencing architecture is awareness of inner aspiration at a prepared locus. Architecture is experiencing original aspiration at that locus. It seems miraculous that anyone could ever do this, yet we have many examples over time and across humanity. Project-based conceptual thinking of planning to facilitate the provision of architectural value informs any scale in the world-as-urban and comprehends the limitations of technological urbanism. (Karassowitsch 2016) 


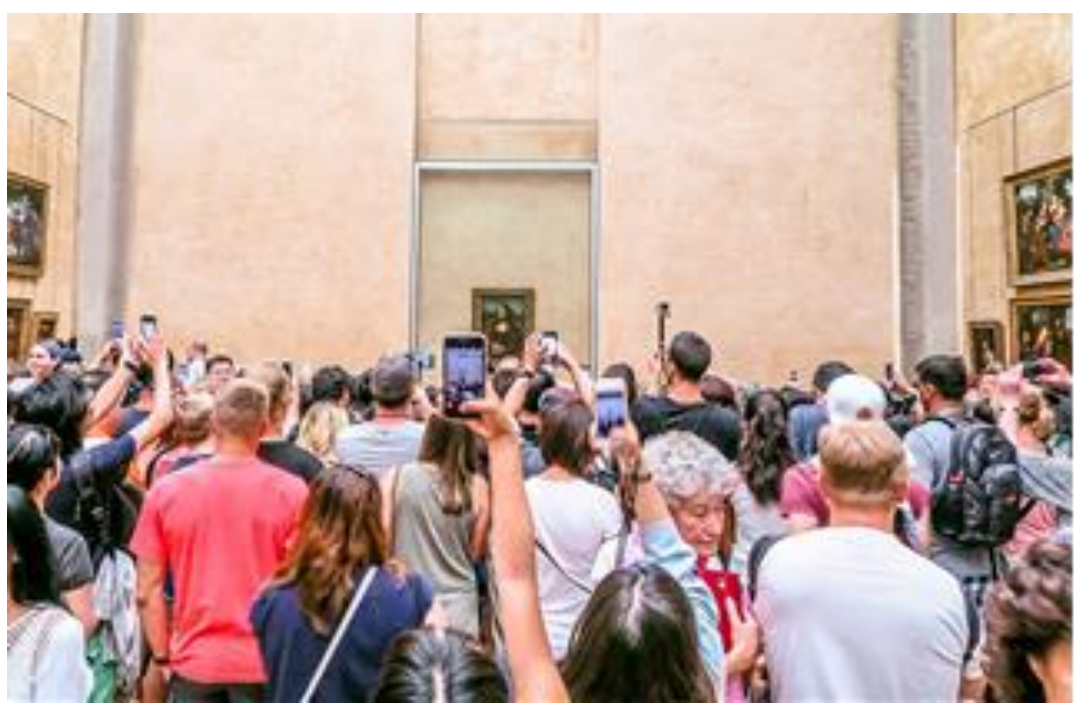

Figure 5. The Mona Lisa by Leonardo Da Vinci is seen but not seen.

Source: https://www.keepcalmandwander.com/

Moreover, preparation for architectural presencing inherently part of Nature as we all are. We are all dependent on love and we claim the need for quality of life for the wellbeing of those whom we love, including ourselves. As we find ourselves in our world where valuation is reductive object measurable terms of science and technology, the beautiful soft subtlety of love and life's meaning is concealed. Architecture at a locus provides for aspiration, even if this is concealing in materialist objectivity as technology. This is the same at building, city or ubiquitous global urban scalse.

Architecture as super ordinate program is, therefore, as value original to consciousness whose only sibling is spirituality. Not religion, but the inner value of heartful evolution and practice the experience of each of us. Spirituality is the inner form of the freedom-of-choice in individuality and freedom-of-duty to life's purpose, while architecture is the worldly outer form of this experience, which we confront when we take action. The current transition that we face is not only away from all fossil hydrocarbon power generation and $\mathrm{CO} 2$ or other greenhouse gasses. It must be away from the values and expectations embodied as tapping the power of nature in ways that kill its life. In part, mitigation of technology's harm, which we call sustainability is needed. But technology must evolve, as it has been for millennia, to a form we will no longer call technology. Architecture's capacity is such that it supersedes current technology in comprehending aspiration and wellbeing. This can be evolved in practice. See Figure 4. Developing after-technology architecture is for other papers. This paper is about evoking that capacity.

\section{Four Strategic Parameters Toward Metabolism of Settlements}

Accepting the possibility of an after-technological transformation lead by architecture based in the spiritual evolution of all of us, the following 4 elements are developed to challenge attaining urban metabolism that must interact with consciousness. This becomes a project based on architecture's superordinate programme to serve spirituality through environments that support the responsibility that consciousness gives us.

\section{1. separation of urban functions}

\section{becomes cooperative whole of transformed after-technological settlements}

The urban superimposes across the world while the rural supersedes the urban where it occurs. Rural settlements derive a functioning structure from the landscape based on its whole intensity, integrated with nature in the way that rural settlements are created with the Land, rather than urban settlements 
that impose on and oppose nature. This may begin with farming in the tradition of Vāstu, and as we see in Feng Shui and others, deep interactivity with consciousness as part of Nature is millennia old.

Our current technology, including communications, allow for distributed power, services and manufacturing. Distributed technology may provide the means to live in a local manner, in many places, with minimal shipping. This allows new settlements to break away from overarching infrastructure and the unresponsive regulation that it brings. Systems can be light and the hardware needs to be light. This growth of would de-emphasize density (i.e. as not a priori bad or good) and prioritize integration of distributed services and integrated with of the Land. This begins to absorb the city and its division. We all live in the Land, no matter what the structures we make appear as. This may include all production of higher quality with changed motives for mass iterative production.

If planning cities aspires the experience of architecture, which is by nature service to human aspiration, the relationship between the Land and settlements will change. Architecture can only be living and production will turn to nature as nature produces. The city will dissolve within the current urbanized world as the rural supersedes urban structure.

\subsection{Lowenvironmentalquality}

\section{high quality environments depend on high quality society}

Low environmental quality is a direct result of goals other than well-being. The argument is that if we increase wealth and technological efficacy, we will also increase wellbeing. It is unfortunate to have to recognize that these are circumstantial targets have no obligation to result in well-being, so they have not. The growth of difficulties that do not allow solutions by technical means is becoming undeniable. Climate change, which has not seen any significant remedial results over decades of producing initiatives and agreements, is one of these. Another is the entrenched slums in countries such as India where the development of wealth depends on the very poor. Claims of removing and reducing slums are ongoing, whereas they have only grown. The occasional eradication of a slum is most often like pest removal that only demonstrates the powerlessness of those people, rarely betterment. See Figure 6.

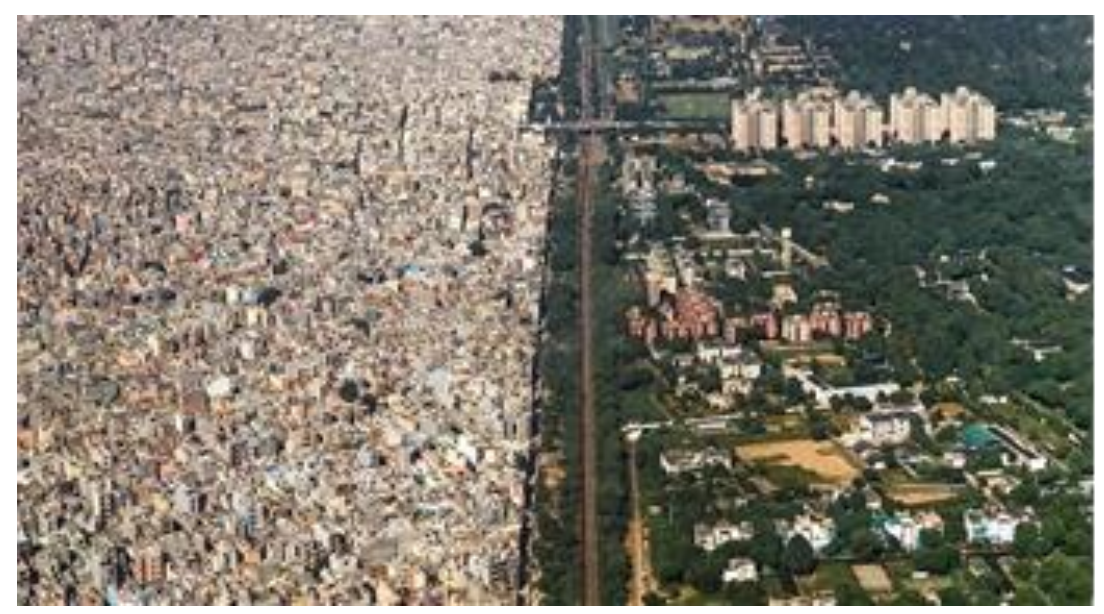

Figure 6. Palam Colony - Raj Nagar and Sadh Nagar, Delhi, India

Architecture as a profession languishes because our professional association's aims are also based on circumstantial goals. Our means for intentional environments are building technology, like a form of equipment. Science and technology is applied to building and physical places. We discuss ways to 'design', (i.e. to use the equipment) within parameters that set a careful limit as to what is asked. Nevertheless, there are responsibilities of architecture that we necessarily cannot leave behind fully while still claiming to be architects and planners. I refer here again to Heidegger's discussion of 
technological action in which society is concealing what technology cannot measure and capture, combining architecture with or subverted in terms of the value of technology. (Heidegger 1977)

Urbanism requires corridors of power that destroy quality to deliver circumstantial goals. Urbanization brings material and power into cities. It changes the Land where the resources are taken. Bringing that harvest to cities' intensified urban locations of habitation also brings a great deal of force against the environments through which such action passes. If we are concerned with wellbeing, the damage to these corridors and spaces of transport for transporting gigantic amounts of material and energy need to be vastly reduced. We are hoodwinked to accept the negatives by circumstantial needs and by inadequacy of our consciousness to feel. Those negatives amount to legions of mentally ill people, and misuse of millions of lifetimes. We may gradually enhance our sensitivity as 'sustainable' solutions are implemented to find that no matter the refinement of process for the speed, tonnage and wattage of movement is to our detriment Technological thinking in the form of norms, appropriating resources and controlling movement is the harm. Lack of sensitivity is not grounds for acceptance. Technology cannot measure wellbeing. We must know our wellbeing from experience within.

High quality environments reflect high quality cultures and societies in this way. Without evolving consciousness we cannot provide for betterment. Architects and planners who gain awareness of architecture's essential character are among those who contribute to 'high quality' culture, reflecting it in the intentional environment. If architecture and planning have wellbeing as a primary goal, they will begin to be activist in supporting higher quality environments.

\section{3. unequal development}

\section{environmental equality decoupled from personal wealth}

Unequal development is the manifestation of our social systems that thrive on inequality and create social and individual issues for exploitation. Inequality is grandfathered in to planning and architecture that have developed based on inequality. The phenomena of our machine ages enframing action of technology is to gain maximum standing reserve in the service of humanity's expansion and the improvement of access to material and power based means. It conceals whatever nature is with its technicist understanding that is expressly not nature's. Technology is not able to discriminate between human and other energy sources. Our 'utilization' of nature's attributes through technical economy and finance does not exclude people's poverty, rather, apparently, the opposite. Because we use this technicist form of knowledge, although we are part of nature, we will not comprehend nature on her terms. Those terms that support all life are subverted. We 'enframe' nature to benefit materially, including our brothers and sisters. Unequal development manifests a system that is does not prioritize wellbeing. Individuals are required to do that.

To express that nature is generous is qualified, since we are an integral part of nature. We would not exist without it nature would not be whole without us. We may perceive nature as generous, but the inherent irresponsibility of current human consciousness in the world requires that our lack of generosity reflects in nature's action. We seek to gain a maximum of power and capacity out of nature's realm as thieves. It means admitting that our current materialist objective science based building technology is a tool that might work for wellbeing but is not bound to. Removing poverty from its integrated role in the economy will mean that our economy and its finance will need to be re-grounded. Cities' functioning with architects and city planners will "build" inequality reveals a mandate for evolution of consciousness or spirituality. The relationship of spirituality to architecture is profoundly important at this point.

The struggle between Edmund Bacon, the Executive Director of the Philadelphia City Planning Commission, and a recognized city planner, and Louis Kahn around planning for the centre of Philadelphia in the 1960s can be taken to express the form this might take. Bacon was. Non Arkaraprasertkul in his 
paper on Kahn's plan and Bacon's plan and opposition brings us to the threshold of the essential quality that keeps us building inequality. (Arkarapasertkul 2008) See Figure 7.

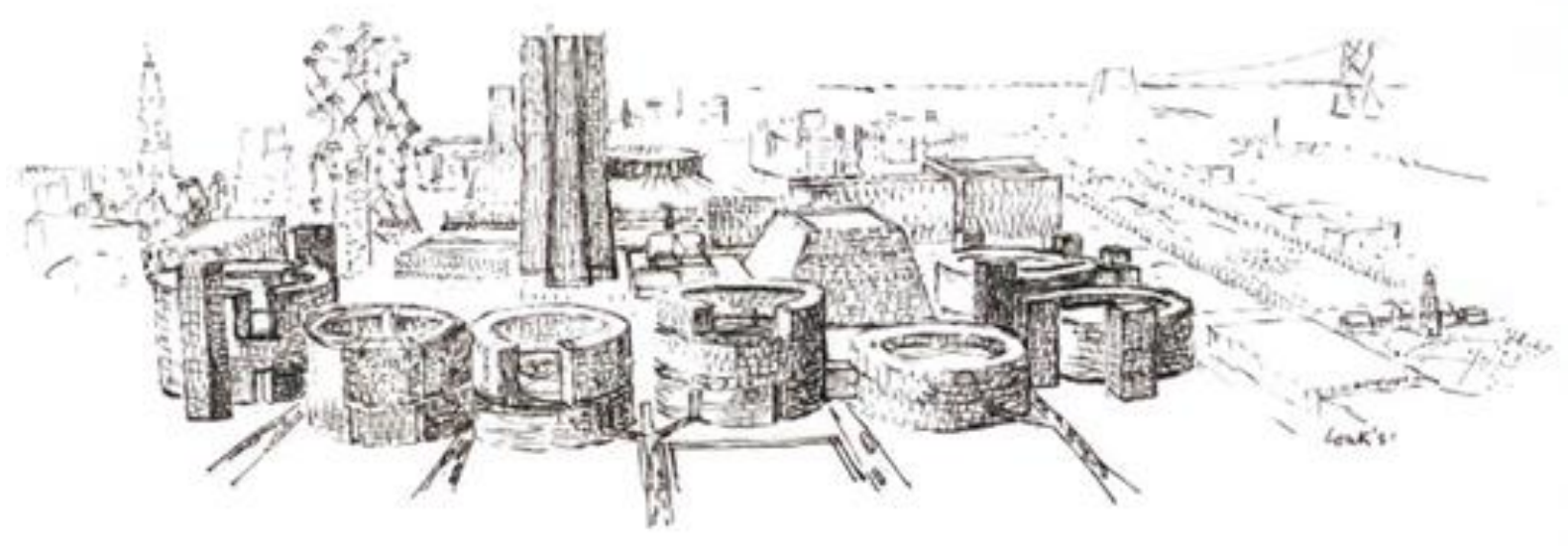

Figure 7. Urban planning and design with an architectural outcome. Louis I. Kahn. 'Civic Center, Project, Philadelphia, Pennsylvania. Source: c. 1957. Digital image (c) The Museum of Modern Art, New York. Licensed by sCala/art resource, New York.

Kahn's proposed re-development of Philadelphia's centre is based on a civic centre. Bacon's creation of city destinations are orientated to adding elements to enhance an unchanged city form while supporting the automobile at all locations equally. Bacon attends the economy. While Bacon claims Kahn was merely scaling up an architectural project to city scale, Bacon's plan provided for buildings around the central city space. The contentious issue of how to handle the automobile resonates with the theme of the postoil city. Both create space for it, but Kahn handles its character as 'fast' and different from walking and other human powered modes of travel, while Bacon claims it must occupy the civic space. Kahn's planning discriminates movement infrastructure that has the attribute of making possible de-linking Philadelphia from being an oil-based city. Bacon's city includes the automobile as an "honoured guest". Bacon considered Philadelphia fully structured, while Kahn planned a layer of infrastructure that addresses wellbeing directly. Kahn's planning for Philadelphia is not post-oil, but it facilitates de-coupling from fossil oil-based power in how he deals with movement. This decoupling comes through Kahn's discrimination of technology and wellbeing.

While the current professional form of planning that is concealing the nature we depend on cannot be excluded, and there lies the trouble: Production that is circumstantial to architecture seems possible from within the space of such technicist practice but nature in this sense can never be absent. Technological economy concealing the possibility of architecture in its means creates unequal development. Equal development would by definition not engage the difference between wealthy and less wealthy people. If the issue is to attain architecture as defined above, as the aim of all human intentional environments, equal development would give everyone quality space, whether made of straw or gold.

\section{4. insufficient support for urban renewal}

\section{urban transformation in light of evolution}

Urban renewal can be a concept of the past. In community informed by the above three points our relationship within nature would create the life that has metabolism that will include cycles of life and evolution. An evolution would be present that is not part of the natural world excluding humanity. Human spirituality is a function of evolution embedded in the very privilege of being human. 
Urban renewal is about the condition which requires us to create separation of urban functions, low environmental quality and promotion of inequality for economic gain. Urban renewal needs, therefore, to be replaced by transformation and evolving metabolism based in rural settlement. The architect, whose realm is conscious awareness, includes the millennia of seeking spirituality's goals and the duty that humanity has within nature as a part of its functioning. The architect is a practitioner of the duty to make gardens on earth, whether it is a machine or of vegetables and flowers. Such living settlements do not need (urban) renewal, they evolve.

\section{Urban Planning Studio of Vellore's Peri-city}

Although spirituality was not an assigned component in the brief of this 4th year studio urban planning and design project, projects that respect rural and natural parameters and space resulted from assigning the four parameters above. This basis necessarily has the other components present in them. There was a clear effect on the outcomes. The Teams asserted their power by evolving priorities for characteristic infrastructure distinct to their peri-city areas. Each team of $+/-2 \mathrm{~km}^{2}$ developed unifying social elements and infrastructure, based on the original rural character in their area. 7 of 8 teams did not directly form residential settlement planning or development. There was great reticence to direct how people arrange their homes. This studio allowed them to express that in an alternative approach that tries to attract life, rather than organize functions. The values that began to define these areas were the features that all people can use. It is a step on the way to the four outcomes. In this case, it is proposed as 7 areas around Vellore that would be points on a ring to stop unplanned development.

The studio outcomes serve as an impression of what kind of development is possible.

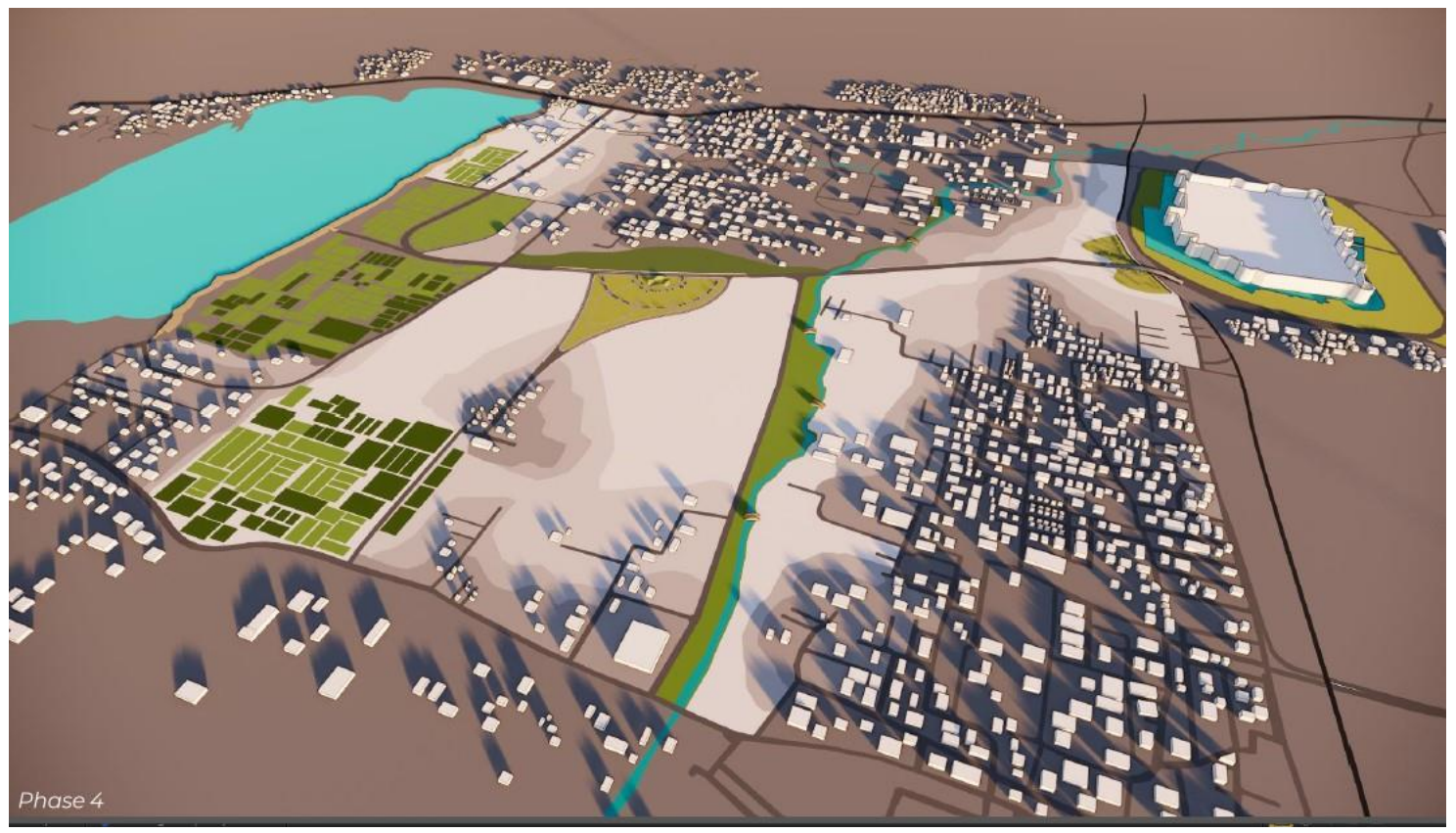

Figure 8. Peri-city Urban TransformNation Project. Sittroor. This project intends functional and infrastructure elements for wider Vellore along with maintaining farming on the southwest. Housing is infill with a variety of density that increases over time. Source. V-SPARC Students: Smeja Shelly Deborah, Chinnambeti Dhedeepya, Bharanishri Gujuluva, Lalitha Bhai Jagadeesan, Edara Yugesh. 

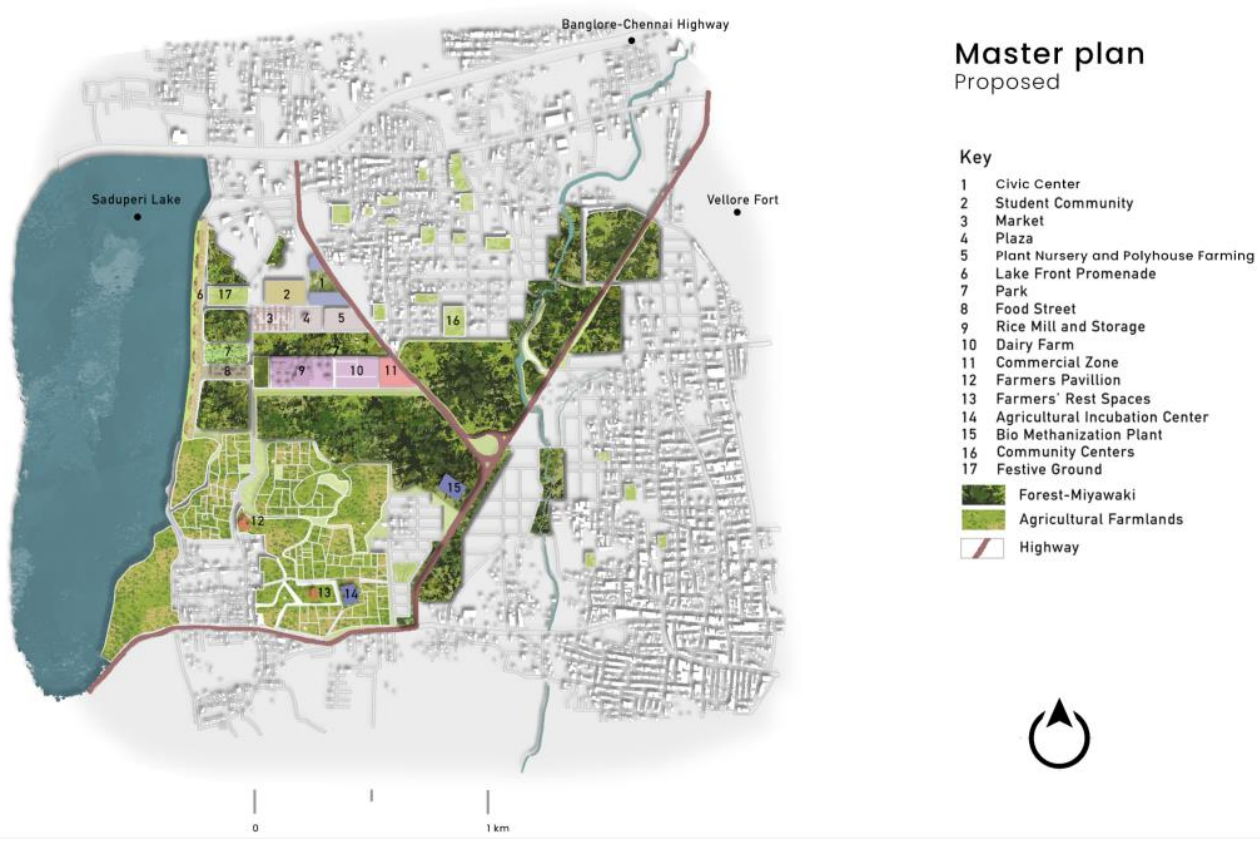

Figure 9. Peri-city Urban TransformNation Project. Ottrumai Puravu. This project intends a green-lung for Vellore along with maintaining farming on the southwest. Housing is infill between salient infrastructure. Source. V-SPARC Students Anusree Anil Kumar, Jabin Biju Thomas, Harshavardhan S, Aravind Balaji T., Brijesh C.S.

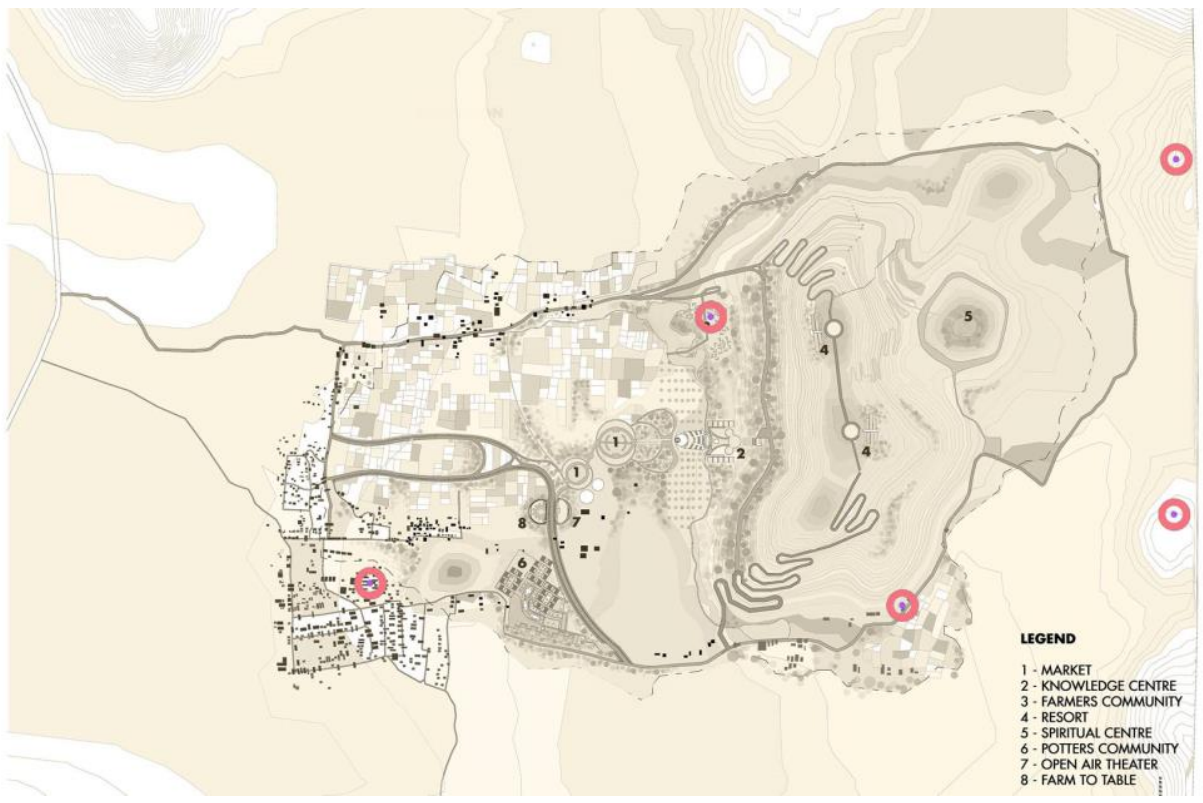

Figure 10. Peri-city Urban TransformNation Project. FarmNation. This project intends recreation and heritage elements for Vellore with maintaining farming on the southwest. Housing is infill between salient features. Source. V-SPARC Students: Athira Suresh, Soorya Sunil, Bharath Kumar, Alex Simon, Sruthi K.

\section{Settlement Transition, Through Architectural Value, to Metabolism}

This paper intersects spirituality as an original core value to architecture and architectural value with planning practice, whereby architectural value must supersede technological values that cannot measure what makes us human. There is no real or net improvement in wellbeing and detriment to the natural world because technology and the problem/solution structure of inquiry do not inherently serve life. The scientific and technological narrow appropriation of nature's process dismembers metabolisms around 
the world. Technology as we know it is based on excessive mobilization on energy. Urbanity will be undermined in a society that seeks balancing those values. It is clear, however, that architecture serves wellbeing. Approaching these four strategic parameters for values informed by consciousness as natural to the world are essential to planning to allow architectural value in form that supports metabolism in environments and supersedes the ubiquitous global urban, like rural settlements do.

\section{References}

Anonymous (2004) Architecture of Mānasāra. Translation from Original Sanskrit. Trans. Prasana Kumar Acharya. Mānasāra Series, ed. Prasana Kumar Acharya, Vol. 4, Delhi: Low Cost Publications.

Arkaraprasertkul, N. (2008) Toward Modernist Urban Design: Louis Kahn's Plan for Central Philadelphia, in Journal of Urban Design, Vol. 13, No. 2 177-194.

Bernstein, B. (November 2018). 'Why the Field of Architecture Needs a New Business Model', in Architectural Record, Ed. McGuigan, Cathleen, Troy: BNP Media.

Ram Chandra (Shajahanpur) (2009) Complete Works of Ram Chandra Volume One. Complete Works of Ram Chandra, 5th Printing ed., Vol. Volume I. Kolkata: Spiritual Hierarchy Publication Trust.

Anonymous (2005) The Cloud of Unknowing. Trans. Evelyn Underhill. NY: Dove.

Heidegger, M. (1977) The Question Concerning Technology, and Other Essays (1955). Trans. William Lovitt. Torch Books, New York: Harper.

Karassowitsch, M. (2015) Architecture is not Technology: The space of differentiation in architectural education. Open House International. Gateshead, Tyne and Wear: The Urban International Press.

Karassowitsch, M (2016) Spirituality, Bigness and Monumentality: Architectural practice and technology [Online]. Available at: https://www.academia.edu/9593167/Spirituality_Bigness_and_Monumentality _Architectural_practice_and_technology_2015 (Accessed: 14 October 2020).

Karassowitsch, M (2016) The Goal in Architecture. The mutual claiming of won another of spirituality and architecture. Dissertation. Akademie der bildende Kunst Wien. Unpublished.

Larson G. J., Bhattacharya R. S. (2008) Yoga: India's Philosophy of Meditation. Encyclopedia of Indian Philosophies. ed. Ram Shankar Bhattacharya Gerald James Larson, 1st ed., Vol. 12 Delhi: Motilal Banarsidass Publishers Private Limited.

McCarter R. (2009) Louis I. Kahn. Architecture in Detail. Phaidon Press.

My Architect (2003) Directed by Nathaniel Kahn [Film]. New York: New Yorker Films.

Primeval: Enter the Incomappleux (2016) Directed by Damien Gillis [Film]. Kootenays: Valhalla Wilderness Society.

Ripple W. J., Wolf C., Newsome T. M., Barnard P., Moomaw W. R. (2019) 'World Scientists' Warning of a Climate Emergency' Bioscience Vol. XX No. X

Rudofsky B. (1964) Architecture without architects, an introduction to nonpedegreed architecture. New York: Museum of Modern Art.

Ruskin, J. (1984) Seven Lamps of Architecture (1894). New York: Farrar, Straus and Giroux.

Thornton, S. "Karl Popper", The Stanford Encyclopaedia of Philosophy (Fall 2018 Edition), Edward N. Zalta (ed.), URL=https://plato. stanford.edu/archives/fall2018/entries/popper/ Visited: August 142020.

Vivekananda (Swami) (1978) Raja-Yoga or Conquering the Internal Nature (1896). Trans. Swami Vivekananda. Dt. Champawat, Uttarakhand: Advaita Ashram. 